\title{
The Effect of Polymer Pin Ribs on Reinforcement of Sandwich Structures
}

\author{
Ladislav Fojtl $^{1,2}$, Lukas Manas ${ }^{1,2}$, Sona Rusnakova ${ }^{1}$ \\ ${ }^{1}$ Department of Production Engineering, Faculty of Technology, Tomas Bata University in Zlín. Vavrečkova 275, 76001 \\ Zlín. Czech Republic.E-mail: fojtl@ft.utb.cz, rusnakova@ft.utb.cz, zaludek@ft.utb.cz \\ ${ }^{2}$ Centre of Polymer Systems, Tomas Bata University in Zlín, Trida Tomase Bati 5678, 76001 Zlín, Czech Republic
}

\begin{abstract}
This research paper deals with an influence of reinforcing polymer ribs on selected mechanical properties of sandwich structures. Reinforcing epoxy ribs are produced directly by the vacuum infusion technology when resin during its flow fills the prepared holes in the polymer core. In the experiment, two rib sizes (diameters) were tested as well as two variants of hole patterns on the core surface. The possible influence of the core material was evaluated on two core material types with different thicknesses. In addition to the observed mechanical properties observed, the types of failure and changes of the sandwich panels weight were also characterized. The obtained results show a significant increase in flexural strength and stiffness of all types and shapes of prepared reinforcing polymer ribs. Positive effect was also observed in the case of edgewise compression load capacity.
\end{abstract}

Keywords: sandwich structure, polymer rib, foam core, vacuum infusion, flexural properties, edgewise compression

\section{Introduction}

Sandwich structures are a special group of composite materials that consist of two thin composite face sheets (facings) with high flexural stiffness and strength and low density core between them. Several materials are used for cores, namelly honeycombs, metal foams, cork and wooden cores and mostly polymer foams [1-3]. Physical properties of foams depend on their cells, where higher mechanical properties exhibits foams with closed cells [4]. Final properties of resulting sandwich structure depend on the facing/core bond quality. This joint between individual sandwich structure parts can be improved by reinforcing ribs that are connecting upper and lower face sheet through a foam core [5]. Appropriately chosen polymer pin ribs then also increase strength and stiffness of the foam core. Hence researches have still been carried out on the reinforcement of polymer foam cores. Wang et al. [6] compared the influence of five rib sets of foam composite sandwich assemblies with different hole densities, where pins were produced by needles. The load carrying capability is reported to be improved significantly and also peak loads of the load-displacement curves increased with increasing hole density. Marasco et al. [7] investigated the effect of reinforcement of sandwich structures with Rohacell core using stitching and creation of X-Cor ${ }^{\mathrm{TM}}$ and $\mathrm{K}-\mathrm{Cor}^{\mathrm{TM}}$ carbon fiber pins. They investigated that these special types of Z-pinned cores exhibit higher specific stiffness than conventional sandwich cores, but lower strength. Furthermore, it is stated that Rohacell foam may be removed without a significant performance penalty (excluding compression loading applications) saving up to $50 \%$ of sandwich panel weight. The effect of titanium alloy pins and carbon pins inserted into Rohacell core of three different thicknesses on compression properties was studied by Cartié et al. [8]. Yingying et al. [9] and also Long et al. [10] studied Z-pin reinforced foam core sandwich panels subjected to indentation and adhesion mechanical tests. The results showed that improved peeling strength was attributed to the linear bonding link between the foam core and the face sheets that was provided from partially-cured Z-pins. In addition to previously mentioned experimental research, number is also focused on modeling and FEM simulations [11]. Liu et al. [12] theoretically investigated the collapse response of sandwich beams having pin-reinforced foam cores in three-point bending and compared results with finite element simulations. Results showed that the weaker the foam is, the more optimal the pin-reinforced foam core becomes. Moreover, reinforcing ribs have significant impact on load carrying capacity - compression strength. Lei at al. [13] investigated experimentaly, theoreticaly and by FEA the effect of polymer ribs in PVC-foam sandwich structures. Failure appearance that occurs during edgewise compression is associated with the properties of the core (density, stiffness and shear strength) and properties of facings, in particular their thickness [14,15].

The aim of presented paper is to investigate the influence of polymer pin ribs with various pin diameters and pin patterns on bending stiffness and strength of resulting sandwich structures having various foam core material and thickness. Moreover, the effect of this pin ribs on edgewise compression strength is also evaluated in the experimental measurements.

\section{Experiment}

For the purposes of the experiment, the most suitable materials that are used mainly in rail and transport industry were selected. Production technology and chosen mechanical tests correspond to those required and used in technical practice.

\subsection{Materials}

In this experimental study, two types of core materials were pin-reinforced. Namelly, Airex T90.100 PET foam with thickness of $10 \mathrm{~mm}$, and Airex C70.55 PVC foam with thickness of 10 and $15 \mathrm{~mm}$, both with close cells in structure. Selected physical properties are given in following table (Tab. 1).

In total, fifteen different kinds of core were prepared and are listed in Tab. 2. Non-reinforced (plain) core was prepared as reference structure for comparison. Holes in 
foam core panels were drilled having two diameters; 2 $\mathrm{mm}$ (samples marked by number 2) and $4 \mathrm{~mm}$ (samples marked by number 4) by 3-axis CNC milling machine, programed in Siemens NX 10. Furthermore, two hole patterns were programed and manufactured on panels having hole density of 2 holes $/ \mathrm{cm}^{2}$ (pattern A) and 4 holes $/ \mathrm{cm}^{2}$ (pattern B). Prepared patterns are depicted in Fig. 1. Distance between individual holes was chosen with respect to final testing sample dimensions.
Tab. 1 Selected properties of core materials

\begin{tabular}{|l|c|c|}
\hline & $\begin{array}{c}\text { AIREX } \\
\text { T90.100 }\end{array}$ & $\begin{array}{c}\text { AIREX } \\
\text { C70.55 }\end{array}$ \\
\hline Density $\left[\mathrm{kg} / \mathrm{m}^{3}\right]$ & 110 & 60 \\
\hline Compressive strength [MPa] & 1.4 & 0.6 \\
\hline Compressive modulus [MPa] & 85 & 69 \\
\hline Shear strength [MPa] & 0.80 & 0.85 \\
\hline Shear modulus $[\mathrm{MPa}]$ & 20 & 22 \\
\hline
\end{tabular}
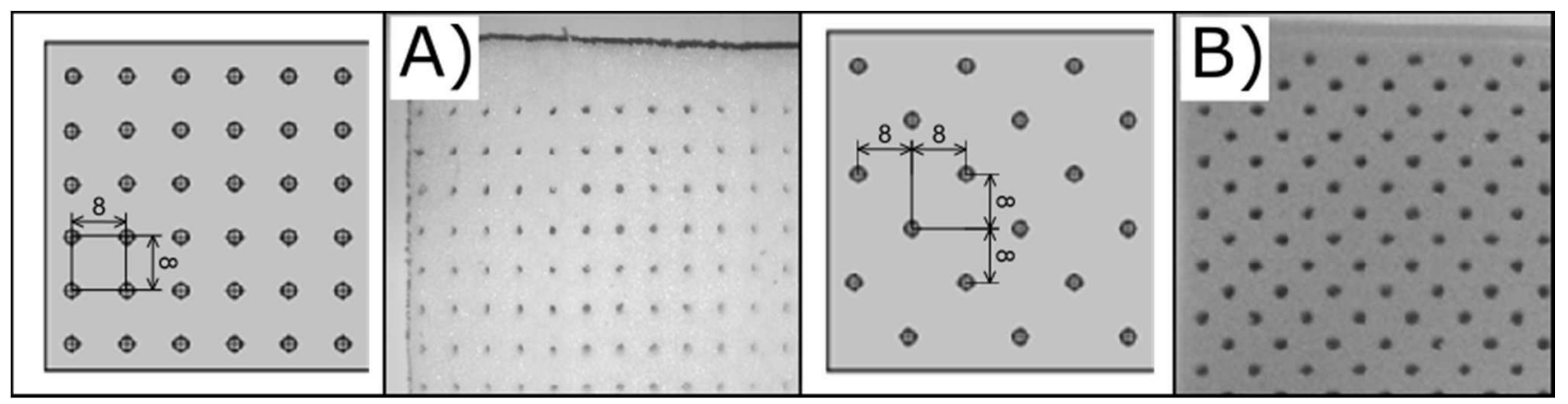

Fig. 1 Hole patterns in core plates; A) 4 holes $/ \mathrm{cm}^{2}$, B) 2 holes $/ \mathrm{cm}^{2}$

The face sheets of the manufactured sandwich panels were composed of four layers of plain weave glass fabric with an areal density of $200 \mathrm{~g} / \mathrm{m}^{2}$. The stacking sequence of the facing composite was $\left[0^{\circ} / 45^{\circ} /-45^{\circ} / 0^{\circ}\right]$. Biresin CR80 and CR82 together with hardener CH80-1 were used as resin matrix.

Tab. 2 Specification of the sandwich structure specimens

\begin{tabular}{|c|c|c|c|c|}
\hline Specimen & Core material & Core thickness [mm] & Rib diameter [mm] & Hole Pattern \\
\hline I_10 & PVC foam & 10 & - & - \\
\hline I_10_A2 & PVC foam & 10 & 2 & A \\
\hline I_10_A4 & PVC foam & 10 & 4 & A \\
\hline I_10_B2 & PVC foam & 10 & 2 & B \\
\hline I_10_B4 & PVC foam & 10 & 4 & B \\
\hline II_10 & PET foam & 10 & - & - \\
\hline II_10_A2 & PET foam & 10 & 2 & A \\
\hline II_10_A4 & PET foam & 10 & 4 & A \\
\hline II_10_B2 & PET foam & 10 & 2 & B \\
\hline II_10_B4 & PET foam & 10 & 4 & B \\
\hline I_15 & PVC foam & 15 & - & - \\
\hline I_15_A2 & PVC foam & 15 & 2 & A \\
\hline I_15_A4 & PVC foam & 15 & 4 & A \\
\hline I_15_B2 & PVC foam & 15 & 2 & B \\
\hline I_15_B4 & PVC foam & 15 & 4 & B \\
\hline
\end{tabular}

\subsection{Specimen Fabrication}

Non perforated (reference) sandwich panels were prepared by hand lay-up followed by vacuum bagging technology. Pin-reinforced sandwich panels were manufactured using vacuum assited resin infusion molding (VARIM). During this process, epoxy resin matrix infuses between individual glass fabric layers and flows through holes in core material. Sandwich panels were filled from their middle ensuring that the resin flows to both sides of a panel equally (Fig.2). All panels were cured at room temperature of $23^{\circ} \mathrm{C}$ for 24 hours with no additional post curing. After resin is cured, pin ribs are created in holes, rigidly connecting top and bottom face sheets of sandwich panel.

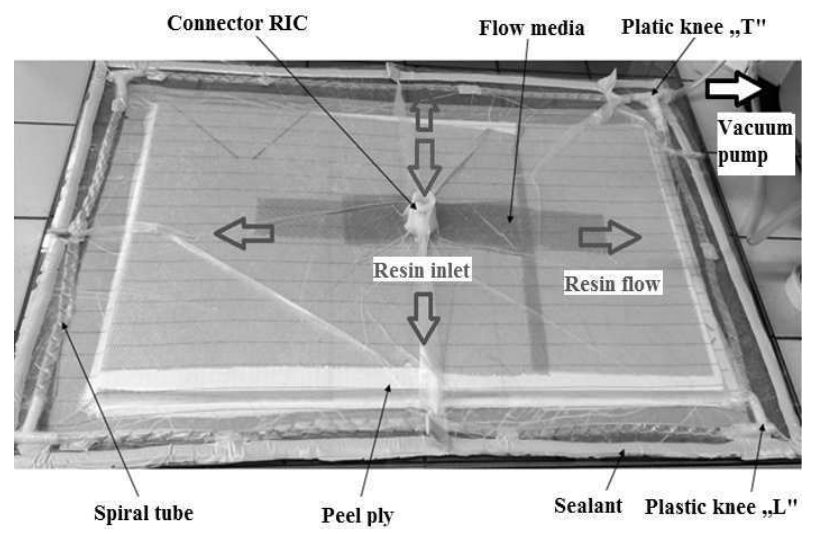

Fig. 2 Sandwich panels manufacturing - VARIM process 


\subsection{Mechanical Testing}

Three-point bending tests (3PB) to determined flexural properties were carried out according to ASTM C393 standard, on a ZWICK 1456 universal testing machine [16]. The span length was equal to $150 \mathrm{~mm}$, where supports had diameter of $5 \mathrm{~mm}$. All specimens were tested dat constant crosshead speed of $5 \mathrm{~mm} / \mathrm{min}$. Sample dimensions for this bending tests were $210 \times 45 \times 10$ (15) $\mathrm{mm}$. Totally, ten specimens were tested for every sandwich panel type and maximal flexural strength $(\sigma f)$ and flexural modulus (Ef) were recorded by the TestExpertII software.

Moreover, edgewise compression tests were conducted according to ASTM C364 using same testing machine as in case of bending tests [17]. Compression force was applied at a rate of $5 \mathrm{~mm} / \mathrm{min}$. Sandwich specimens were cut from the panel having dimension of $80 \times 50 \times 10$ (15) $\mathrm{mm}$. All measurements were conducted at ambient temperature $\left(23^{\circ} \mathrm{C}\right)$ for eight specimens from every sandwich type. During tests, maximal force is recorded and subsequently, edgewise compression strength $(\sigma)$ is calculated using Eq.1. All sandwich testing specimens were obtained by cutting from manufactured panels by diamand blade saw [18].

$$
\sigma=\frac{F_{\max }}{\left(2 \cdot t_{f}\right) \cdot w}[M P a]
$$

Where:

$\mathrm{F}_{\max } \ldots$ Maximal force measured in experiment $[\mathrm{N}]$,

$\mathrm{t}_{\mathrm{f}}$...Face sheet thickness $[\mathrm{mm}]$,

w...Sandwich specimen width [mm]. [17]

\section{Results and Discussion}

Evaluated results of measured parameters are shown in bar graphs in Fig. 3 (results for flexural modulus) and Fig. 4 (results for flexural strength). Horizontal lines in graphs represent reference values measured for non-perforated sandwich specimens, where exact value is in black frame and corresponds to the $100 \%$. Depicted procentual values show total increase of mean values of evaluated parameter. As can be seen, reinforcing ribs with a diameter of $4 \mathrm{~mm}$ increase both evaluated parameters more than ribs with a diameter of $2 \mathrm{~mm}$. Reinforcing ribs increase flexural modulus (Fig. 3) more in PVC foam core (Specimens I_10) than in PET foma core structures (Specimens II_10). The highest percentage enhancement in flexural modulus was achieved in samples I_15_A4, specifically in PVC foam cores of $15 \mathrm{~mm}$ thickness with $4 \mathrm{~mm}$ reinforcing ribs in hole pattern A. As is visible from the same graph, values of flexural modulus of stuctures with reinforcing ribs in the pattern A with PVC foam is identical to the modulus of PET foam structures with the same hole pattern. This fact can also bring some financial and weight savings in sandwich structures having the same mechanical properties. The same improvement is also observed in the values of flexural strength (Fig. 4). Even in the case of this parameter, the same increasing trend is observed, for example, the strength of specimens I_10_A4 is up to three times higher compared to the nonperforated structure and shows the highest flexural strength of the sandwich structures tested.

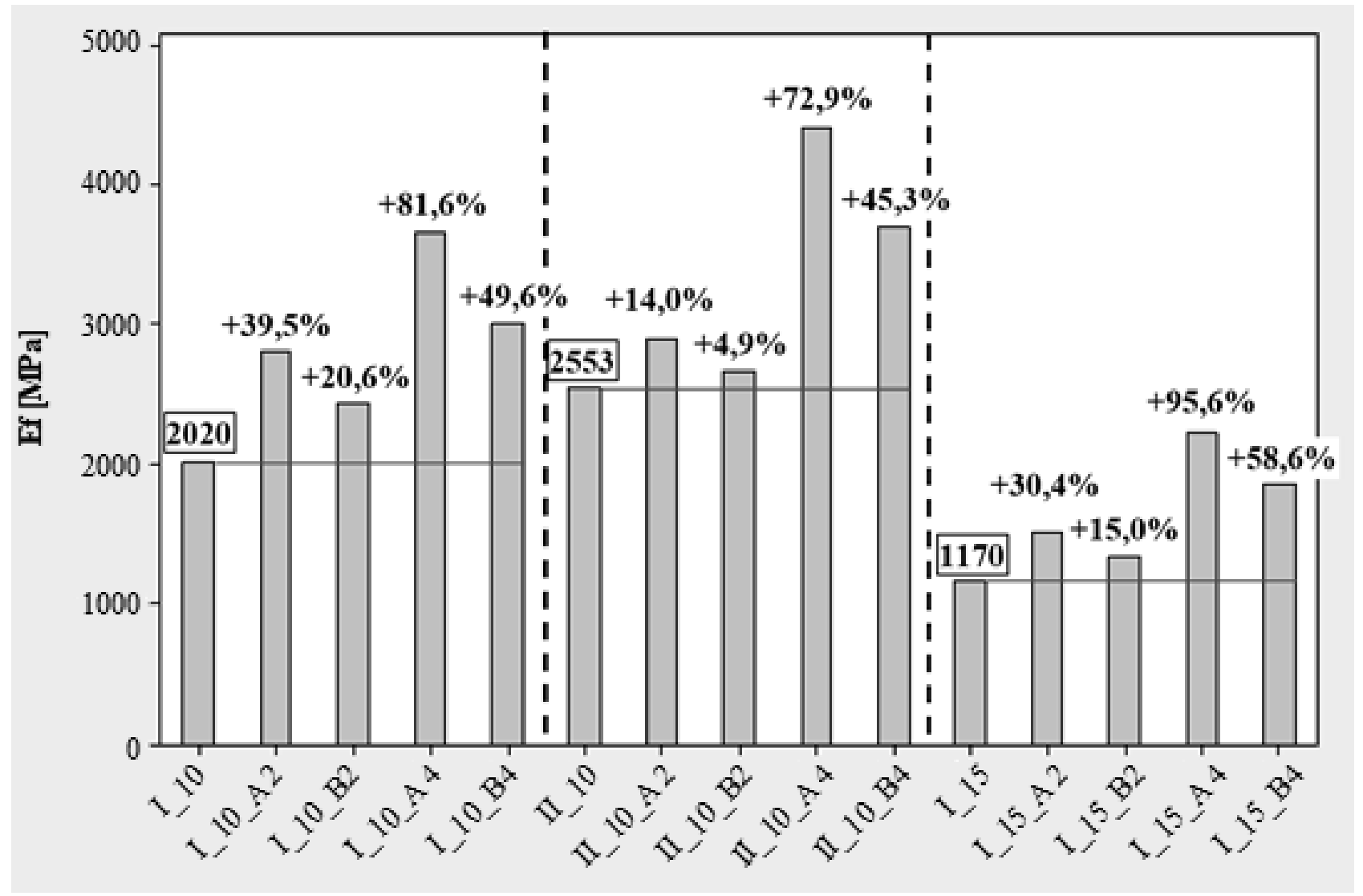

Fig. 3 Flexural modulus of prepared sandwich structures in $3 P B$ 


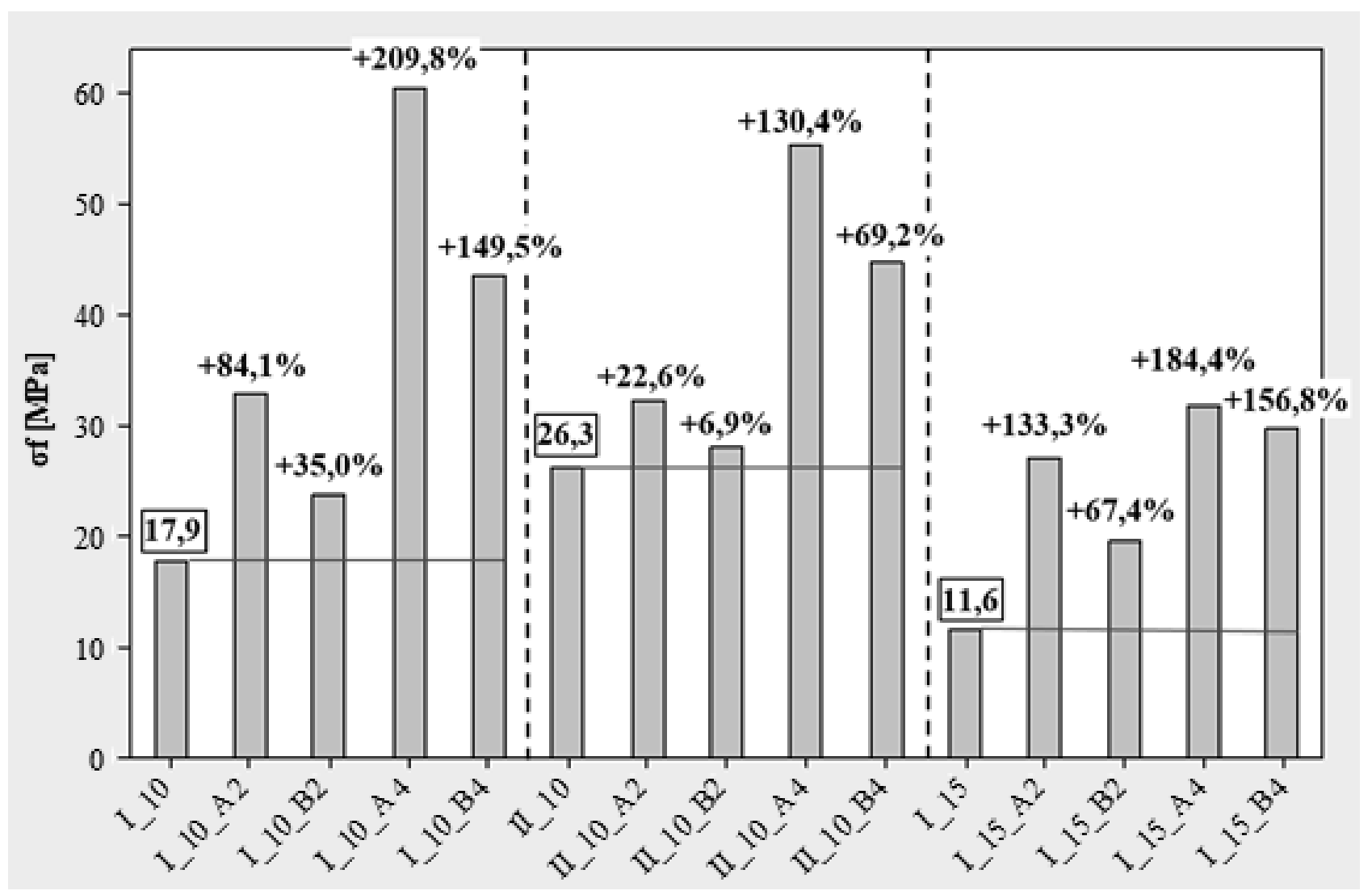

Fig. 4 Flexural strength of prepared sandwich structures in 3PB

Moreover, the failure modes were observed during the measurements of flexural properties for all sandwich structures. In case of non-perforated (reference) strucures with PVC foam core of both thicknesses, local face sheet wrickling followed by core crushing was observed. Furthermore, fibre cracking in upper facing under loading pin due to increased stress from normal forces located in this area was identified. Same failure was observed also for reinforced structures A2 and B2. On contrary, reinforced structures with pin ribs of $4 \mathrm{~mm}$ diameter showed core shear failures, where crack propagates from upper to lower facing causing polymer ribs cracking. This failure appeared because of higher stiffness of whole sandwich construction resulting from polymer ribs. In sandwich structures with PET foam core (group identified by II), identical local failure was observed for non-perforated specimens. Conversely, shear defect of the core already occurred in case of reinforced structures. This fact is attributed to considerably higher mechanical properties and density of PET foam compared to PVC foam.

Data calculated from obtained values of maximal force in edgewise compression tests are depicted in graph in Fig.5. As can be seen, the effect of reinforcing ribs in structure is also very significant. The highest increase in strength was measured for sandwich structures with 10 $\mathrm{mm}$ thick PVC foam, specifically up to about $250 \%$ in case of specimens A4. In the case of PET core structures, the strength parameter was slightly reduced, but the values varied in the interval of $\pm 1 \mathrm{~s}$ (standard deviation).More significant strength increase was measured for the stuctures reinforced with ribs of $4 \mathrm{~mm}$ diameter. For samples of III group (15 mm PVC foam), an increase in edgewise copression strength was observed, but not as significant as in $10 \mathrm{~mm}$ thick core samples. The largest increase of $91 \%$ was calculated for structures with reinforcing ribs of $2 \mathrm{~mm}$ diameter in the hole pattern A.

As for bending tests, typical failures were observed during edgewise compression tests. For both structures with core thickness of $10 \mathrm{~mm}$, shear crimping of non-reinforced specimens was observed, however all other types of tested sandwich specimens shown compressive core failure with facings delamination probably due to much higher stuctural rigidity. Moreover, typical facing delamination from foam core was detected for non-reinforced structures with core of $15 \mathrm{~mm}$ thickness (specimens I_15). On contrary, pin reinforced structures A2 and B2 were characterized by their compresive core failure. Structures reinforced by higher pin diameter (A4 and B4) shown facing fracture followed by core shear failure through its thickness.

For overall comparisson of polymer pin ribs benefit, it is also necessary to mention the weight changes of individual sandwich structures. Manufactured panels were cut, dimensions measured and weighted and futher recalculated to weight in kilograms per $1 \mathrm{~m}^{2}$. Individual results are shown in Tab. 3. It can be seen that reinforcing ribs increase resulting weigth of sandwich panel. Increase in weigth of $25-55 \%$ was measured in case of $2 \mathrm{~mm}$ diameter ribs, and rise about $65 \%$ for B4 and $100 \%$ for A4 was also evaluted for $4 \mathrm{~mm}$ diameter ribs. 


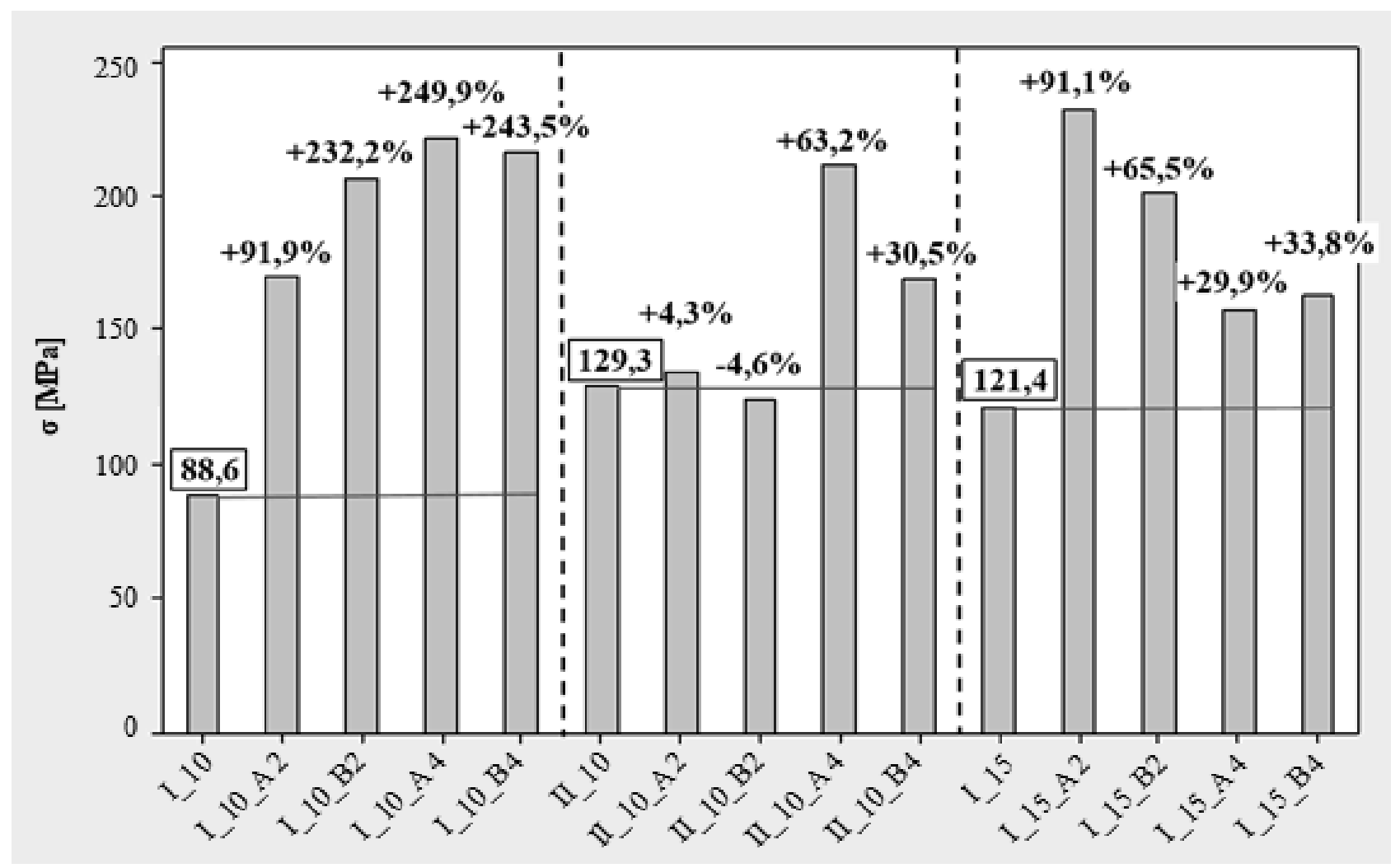

Fig. 5 Edgewise compression strength of prepared sandwich structures

Tab. 3 Areal weight of prepared sandwich structures

\begin{tabular}{|c|c|c|c|c|c|}
\hline Specimen & Areal weight $\left[\mathbf{k g} / \mathbf{m}^{2}\right]$ & Specimen & Areal weight $\left[\mathbf{k g} / \mathbf{m}^{2}\right]$ & Specimen & Areal weight $\left[\mathbf{k g} / \mathbf{m}^{2}\right]$ \\
\hline I_10 & 3.19 & II_10 & 4.06 & I_15 & 3.89 \\
\hline I_10_A2 & 4.97 & II_10_A2 & 5.41 & I_15_A2 & 5.94 \\
\hline I_10_A4 & 6.62 & II_10_A4 & 7.80 & I_15_A4 & 7.98 \\
\hline I_10_B2 & 4.35 & II_10_B2 & 5.06 & I_15_B2 & 5.37 \\
\hline I_10_B4 & 5.64 & II_10_B4 & 6.55 & I_15_B4 & 6.30 \\
\hline
\end{tabular}

\section{Conclusion}

The research has evaluated the possibility to improve mechanical properties by reinforcing polymer ribs that are created in sandwich structure during its manufacturing proces - vacuum assited resin infusion molding. The obtained results in three-point bending indicate that polymer ribs increase values of both, bending modulus and strength. Furthermore, in case of specimen edgewise compression, reinforcing ribs have positive impact on load capacity, or rather edgewise compression strength. Therefore, it can be concluded that with growing rib diameter, mechanical properties are increasing, however sandwich panel weight is also growing due to higher volume that is occupied by crosslinked resin at the expense of foam core volume. This fact has to be taken into account during design phase of sandwich constructions and products.

\section{Acknowledgement}

This publication was written with support of the project Technology Agency of the Czech Republic (TAČR) "Centre of Advanced Polymeric and Composite Materials" (TE 01020216). The authors are also grateful to
Operational Program Research and Development for Innovations, co-funded by the European Regional Development Fund (ERDF), and the National Budget of the Czech Republic, within the framework of the project Centre of Polymer Systems (reg. number CZ.1.05/2.1.00/03.0111) and project CPS Plus (reg. number CZ.1.05/2.1.00/19.0409). Furthermore, this research was also carried out with support of the Ministry of Education, Youth and Sports of the Czech RepublicProgram NPU I (LO1504). The authors also gratefully acknowledge the financial support of this research by the internal grant of Tomas Bata University in Zlin No. IGA/FT/2018/004 funded from the resources of specific university research.

\section{References}

[1] LEHMHUS, D., BUSSE, M., HERRMANN, A., KAYVANTASH, K. (2013). Structural Materials and Processes in Transportation, p. 598. WileyVCH Verlag GmbH, New York.

[2] MÜlLER, M., RUGGIERO, A., VALÁŠEK, P. (2017) Mechanical Characterisation of Metal/Polymeric Composite Waste/Metal Sandwich Panel. 
In: Manufacturing Technology, Vol. 17, Issue 4, pp. 530-536, ISSN 1213-2489.

[3] JIROUTOVA, D. (2016). Methodology of Experimental Analysis of Long-term Monitoring of Sandwich Composite Structure by Fibre-optic Strain Gauges. In: Manufacturing Technology, Vol. 16, Issue 3, pp. 512-518, ISSN 1213-2489.

[4] YALKIN, H. E., ICTEN, B. M., ALPYILDIZ, T. (2015). Enhanced mechanical performance of foam core sandwich composites with through the thickness reinforced core. In: Composites Part B: Engineering, Vol. 79, pp. 383-391, ISSN 13598368 .

[5] LASCOUP, B., ABOURA, Z., KHELliL, K., BENZEGGAGH, M. (2014). Core-skin interfacial toughness of stitched sandwich structure. In: Composites Part B: Engineering, Vol. 67, pp. 363370, ISSN 1359-8368.

[6] WANG, B., WU, L., JIN, X., DU, S., SUN, Y., MA, L. (2010). Experimental investigation of 3D sandwich structure with core reinforced by composite columns. In: Materials and Design, Vol. 31, pp. 158-165, ISSN 0261-3069.

[7] MARASCO, A. I., CARTIÉ, D. D. R., PARTRIDGE, I. K., REZAI, A. (2006). Mechanical properties balance in novel Z-pinned sandwich panels: Out-of-plane properties. In: Composites Part A: Applied Science and Manufacturing, Vol. 37, pp. 295-302, ISSN 1359-835X.

[8] CARTIÉ, D. D. R., FLECK, N. A. (2003). The effect of pin reinforcement upon the through-thickness compressive strength of foam-cored sandwich panels. In: Composites Science and Technology, Vol. 63, pp. 2401-2409, ISSN 0266-3538.

[9] YINGYING, Z., JUN, X., MUFENG, D., Yong, L. (2014). Experimental study of partially-cured Z-pins reinforced foam core composites: K-Cor sandwich structures. In: Chinese Journal of Aeronautics, Vol. 27, Issue 1, pp. 153-159, ISSN 10009361.

[10] LONG, D., GUIQIONG, J. (2009). Indentation study of Z-pin reinforced polymer foam core sandwich structures. In: Composites Part A: Applied
Science and Manufacturing, Vol. 40, pp. 822-829, ISSN 1359-835X.

[11] KULHAVÝ, P., LEPSIK, P. (2017). Digitization of Structured Composite Plates with Regard to Their Numerical Simulations. In: Manufacturing Technology, Vol. 17, Issue 2, pp. 197-203, ISSN 1213-2489.

[12] LIU, T., CHEN DENG, Z., JIAN LU, T. (2008). Analytical modeling and finite element simulation of the plastic collapse of sandwich beams with pin-reinforced foam cores. In: International Journal of Solids and Structures, Vol. 45, pp. 51275151, ISSN 0020-7683.

[13] LEI, H., YAO, K., WEN, W., ZHOU, H., FANG, D. (2016) Experimental and numerical investigation on the crushing behavior of sandwich composite under edgewise compression loading. In: Composites Part B: Engineering, Vol. 94, pp. 3444, ISSN 1359-8368.

[14] BOCCACCIO, A., CASAVOLA, C., LAMBERTI, L., PAPPALETTERE, C. (2013). Structural Response of Polyethylene Foam-Based Sandwich Panels Subjected to Edgewise Compression. In: Materials, Vol. 6, pp. 4545-4564, ISSN 1996-1944.

[15] HASSAN, S., ASMA, A., TARIQ, A. (2013). Compressive Strength of Different Modes of Failure of Sandwich Structure under Edge Wise Compressive Load. In: Advanced Materials Research, Vols. 816-817, pp. 111-114, ISSN 1662-8985.

[16] ASTM C393/393M-11. Standard Test Method for Core Shear Properties of Sandwich Constructions by Beam Flexure, American Society for Testing and Materials. ASTM Standard. 2012.

[17] ASTM C364/364M-07. Standard Test Method for Edgewise Compressive Strength of Sandwich Constructions, American Society for Testing and Materials. ASTM Standard. 2012.

[18] BÍLEK, O., ŽALUDEK, M., ČOP, J. (2016). Cutting Tool Performance in End Milling of Glass Fiber-Reinforced Polymer Composites. In: Manufacturing Technology, Vol. 16, Issue 1, pp. 12-16, ISSN 1213-2489. 